\title{
Saying Goodbye to 1990s Students and Welcoming New Century Students into the College Classroom: Observations from the Scene of Learning
}

\author{
Patrice Flynn, MSW, MA, PhD \\ Professor of Economics and Business \\ Morrison Professor of International Studies \\ Fulbright U.S. Research Scholar \\ Mount St. Mary's University \\ 16300 Old Emmitsburg Rd, Emmitsburg, MD 21727, USA
}

\begin{abstract}
As college professors say goodbye to students born in the 1990s and welcome "new century" students born in the 2000 s, measurable and profound change is evident in the classroom. This essay documents key behavioral differences between these two groups of students and considers how the needs of new century students have escalated in ways not seen before, causing even skilful professors to pause. Notable are signs of increased nomophobia (fear of being disconnected from mobile devices), information fatigue, human-humanoid singularity, and the inefficacy of antiquated high-impact pedagogies. Early evidence foreshadows more far-reaching transitions in the learning realm for new century students as they matriculate into colleges over the next decade. Perhaps the solution for students, professors, and administrators is to turn over behavioral management of students to big tech, leaving the faculty more time for course content.
\end{abstract}

Keywords: nomophobia, information fatigue, human-humanoid singularity, new century students, high-impact pedagogies, nudge, student behavioral management

\section{Introduction}

Students born in the 1990s are great! They are energetic, nice, funny, curious young people who currently fill the classrooms of colleges and universities the world over, including mine. It has been a pleasure working with this group in a structured learning environment over the past decade. Alas, students born in the 1990s are beginning their transition into post-college life.

This essay is a reflection on the transformation occurring in college classrooms as professors say goodbye to 1990s students and welcome those born in the 2000s, referred to in this essay as "new century" students. The difference between these two groups is profound, especially in the ways new century students learn and their expectations for college professors. What made the 1990s students unique relative to their older and younger siblings? What are some of the salient changes in the behaviors of new century students now matriculating into college? How do students manifest signs of increasing nomophobia (fear of being disconnected from mobile devices), other fear-based anxieties, information fatigue, human-humanoid singularity, ultra-utilitarian learning styles, and the repudiation of antiquated high-impact pedagogical practices? What do such changes portend for skillful and effective teaching in colleges and universities today?

Frankly, the shifts in the college-level learning realm give me pause. It is not in my nature to be critical of students for whom I have a soft spot; I enjoy being an integral part of their learning process. This report from the scene of learning serves as a forum to begin to identify some of the unprecedented behaviors that students have inherited from society and hence bring to the scene of learning. By presenting raw, real-time observations, my aim is to call for a discussion among those of us who have a stake in the human capital development of students. Professors recognize that while student learning needs are ever-changing, the speed and acuteness of current transitions foreshadow far-reaching implications. I believe these shifts will impact how professors channel students' intellectual power during their decisive formative years in college.

This essay is organized into five sections. Following this introduction, section two differentiates between students born in the 1990s and those born in the 2000s - dubbed "new century" students - who are just beginning to matriculate into colleges as this article goes to press. Section three presents direct observations from the college classroom, highlighting the kinds of student behaviors that professors see up-close that point to what is new and different in the modern-day 
college classroom. Section four discusses the impact of changing student behaviors and learning needs on teaching. Section five closes with policy implications to consider if colleges and universities are willing to do the hard work of adapting to a new student body. One option explored is the possibility of turning over student behavioral management to big tech, leaving professors more time for course content.

\section{Differences Between 1990s and "New Century" Students}

Being in the college classroom every day, professors see a clear distinction between students born in the 1990s and those born in the 2000s. One of the milestones of 1990s students was their having witnessed the impacts of the2008-09 Wall Street financial crisis. Perhaps a parent lost a job, or a grandparent had to return to work when life savings were wiped out, or a cousin moved in with the family due to a house foreclosure. While too young to comprehend or process what we now refer to as the Great Recession, children born in the 1990s felt the effects of the crisis as pre-teens and adolescents. This experience focused the 1990s students in ways that are distinct from their older siblings: the edginess is gone; the feeling of entitlement has dissipated; and these students are more open to whatever I can teach them about the capitalist world and their work futures. For the most part, there are few disciplinary problems as their parents did all they could to help their children prepare for college.

Second, 1990s students are unique as the last of the offspring of baby boomers (born between 1946 and 1964). Boomer offspring were a demographic windfall for colleges and universities swamped with applicants. Some institutions were able to bank this windfall while non-savers struggle to recruit enough students to keep the institutions afloat.

Third, students born in the 1990s will be remembered as the last generation to have attended elementary and middle schools without supercomputers in the palms of their hands; in contrast, their successors were introduced to hand-held mobile devices as early as kindergarten. New century students are thus tech-tethered, that is, physically and psychologically attached to mobile devices where texting, tweeting, and image-sharing occur 24/7. Mental health professionals describe being tech-tethered as a form of electronic clinical addiction to be treated thusly (Turkle, 2011; Twenge, 2018). There is even a name now for the condition of Internet deprivation and feeling fearful of not having one's mobile device in-hand: nomophobia. It is no surprise to teachers everywhere that nomophobia was Cambridge Dictionary's 2018 word of the year.

Young people today love their devices. Malcolm Harris's insightful book, Kids These Days: Human Capital and the Making of Millennials, explains how mobile devices allow youth a freedom of expression in their otherwise highlymanaged, productive, and surveilled lives (2018). Mobile devices are a youth's outlet, allowing a space they can enjoy and control. Why criticize or deprive them of this pleasure?

Part of the answer lies in the scientific evidence that Silicon Valley's computational hardware and software, that have swept the planet in a mere 10 years, have re-wired new century students in ways distinct from all previous generations of learners. Day-by-day, professors are witness to this transformation in student learning. Young people have morphed into a new species of homo sapiens, identified by anthropologist Jennifer Robertson as robo sapiens, by which she means an "emergent co-creation between an artificial system and humans" (2007:379). This new species cannot separate the self from an object such as a hand-held supercomputer. The merging of the human and the humanoid is nearly complete, holding out "the possibility that humans and machines will meld into a new, superior species" (Robertson, 2018). Those of us who work with new century students in the college classroom may be witnessing the emergence of this new species as human-humanoid singularity takes form.

It is an understatement to say that teaching new century students is going to be a challenge for those who strive to be effective educators. The merging of the human and humanoid impacts the classroom in ways we do not yet fully understand. Teaching methods honed over decades in college and university classrooms no longer suffice.

As part of my adaptation to the predictable tech-induced shifts over the past decade, I began teaching with an autonomous humanoid robot in the business classroom in 2015 on my own, without tech help. Our class robot captures student interest and imagination (CIC, 2015; Flynn, 2017). Measurable outcomes include: stimulating raw critical thinking, readily applying theory to practice, facilitating non-digital communication, and mediating relationships. The robot helps directly engage students in analytical problem solving, structured v. unstructured decision making, and exploring the core functional areas of business enterprise - all critical to understanding the modern world of business. Learning about and interacting with an autonomous humanoid robot in a structured environment puts my students on the cutting-edge of computational technology and jobs of the future, something I readily facilitate as a labor economist with an eye toward human capital requirements in future workplaces. 


\section{Observations from the Scene of Learning}

Despite having a head start in robotics, I am stumped by what I am seeing since the start of the 2018 academic year, to be precise. Below are some of my observations from the scene of learning: the business classroom at a liberal arts college. The observations are not presented in any kind of order because there is not yet sufficient data from which to recognize patterns or analyze the changes. What I offer is raw reporting for your reflection.

\subsection{Observation \#1: Need to Know}

Students have traditionally been interested in receiving a syllabus at the start of each course that identifies what will be covered throughout the semester and due dates for assignments and examinations. Today's students, however, have an urgency to know specifics at a level not seen before. Not only do students ask when Test \#1 will occur, but they also want to know during the first week of the semester exactly what will be on Test \#1. The stress is palpable. So, I draw a horizontal line on the board with today's date on the far left and the date of Test \#1 on the far right and explain that everything we cover from the first day of class until the day before Test \#1 will be on the first test. Student anxiety drops; we move forward.

Where does this "need to know" stem from? Why the anticipation from day one? Is the pressure to succeed in college dwarfing the ability of students to trust professors and the teaching-learning process we facilitate? Perhaps this is a minor point, but my hunch is that we are going to see anxiety in the classroom escalate over the next decade as college performance is increasingly tied to future economic performance. Students recognize that learning has become increasingly utilitarian and linked directly to the human capital acquisition most likely to result in a job with some semblance of economic security in an environment where money is increasingly taking on the status of oxygen in this ever-increasing global capitalistic model. As such, students want to know ahead of time exactly what will be on an exam, so they can study only what will most likely be on the test.

Today's students ask teachers and tech to think and formulate ideas for them. In many instances, students struggle with analytical skills, a behavior that German philosopher Byung-Chul Han argues is directly related to a phenomenon called information fatigue that youth experience due to prolonged time spent on digital platforms. Han argues that "after a certain point, information ceases to be informative," so students reject information that gives lip service to selfdevelopment and self-autonomy (2017:61).

Unfortunately, the response by college executives is often to mandate that students spend more time online (e.g., Blackboard or Moodle), not less time on the very medium that may be causing distress. As Marshall McLuhan (1964) suggested, the medium is the message.

Students know that tech is doing for them what they used to have to do for themselves, for example, figuring out what is required to get a good grade. Students say it is no longer all that important to attend every class period because "the material is posted online." Tech is taking away what students used to manage on their own while at the same time creating more responsibility. Young people have a lot on their plates as managers of their human capital development, reflected in their urgent need to know. In the digital environment, the priority is the present, in stark contrast to an education that developed an individual's free will. This is something Shoshana Zuboff discusses in The Age of Surveillance Capitalism (2019), whereby big tech, advertising, and money "nudge" people away from self-identified goals and toward commercially-driven actions. Young people are very savvy; they know they live under such surveillance, and they act accordingly. Notable with big data nudging, however, is the potential loss of free will, a critical element in the market system model.

\subsection{Observation \#2: Group Work}

Small group work has been a hallmark of the college classroom to energize learning and allow students time to get to know each other while applying knowledge. Historically, students enjoyed the shift from direct instruction to working with classmates. While providing needed rest from the "sage on the stage" model of learning, group work also provides effective teachers a mechanism to circulate throughout the room and observe student interactions, prompting and/or directing customized learning, where possible.

Since 2017, however, we have lost our ability to facilitate learning through small group work. Unfortunately, when students move into groups today, they immediately turn to their hand-held devices instead of looking up and introducing themselves to other group members. As a result, professors have to re-think group work as a teaching tool and either drop it from set activities or find a way to modify student behavior. This new group work challenge comes on the heels of experiments on how to keep students from looking at mobile devices, a ubiquitous phenomenon in the classroom. 
${ }^{1}$ Over the past two years, I have developed a successful way to manage student adhesion to mobile devices by spending time at the end of the first week of each semester discussing how we will communicate with each other without mobile devices.

By this time, students are fully aware of my keen interest in and knowledge of cutting-edge technologies and they anticipate meeting our class robot. They have begun to trust me. Throughout my teaching 1990s students and new century students, I have discovered the huge advantage gained by bringing in new technologies for student learning (e.g., QR codes for fintech transactions, beacons for pricing, autonomous humanoid robots, app implants, big data, etcetera).

I then request that there be no phubbing in class. When questioned as to what this means, I ask if students have ever been in a conversation where both people are looking into each other's eyes, but one person is texting on a device that is in their lap? That is phubbing. Students smile; heads nod knowingly. I explain that when students phub, it throws me off my game, and I don't want to be off my game when I teach. Students are with me, for now. The interpersonal communication and learning have begun. Lastly, I ask that when students come to class, they place the devices on their desks, face down, so that no one is distracted by the machine. Again, students typically are with me and immediately do so.

This is not the case with many new century students. Whereas 1990s students would place their devices on the desks at the furthest point away from their bodies to make room for note taking, some new century students reacted differently. During the fall 2018 semester, I noticed that a handful of students could not comply. They exhibited trepidation and were moving more slowly, involuntarily paralyzed by their tethered addiction. Some students placed the phone on the desk very close to their bodies with their dominant hand covering the device.

While professors are open to the idea that society is witnessing the next stage of singularity (i.e., the melding of human and artificial intelligence), we may be resisting an inevitable transition. I am wondering if my recent teaching adjustments are merely for my own benefit to manage the classroom and whether the adjustments create a cognitive dissonance in students' brains between my teaching methods and their increasingly data-driven lives.

Some of us professors try hard not to get angry with students, or become judgmental of their technology, or appear harsh. We enjoy our students and the teaching environment. However, we desire an effective set of regulations that everyone can follow so that we do not have to police behavior. Such techniques are in sync with those of Harvard behaviorist B.F. Skinner, founder of behavioral modification theory-the idea that behavior is determined by its consequences, be they reinforcements or punishments. Skinner appealed to a society "that met [hu]men's needs by limiting freedom, uniqueness, and nonconformity," concepts he believed impeded the development of society (Krill, 1974:305).

Shoshana Zuboff, a student of Skinner, argues that today's forms of behavior modification - evident in surveillance capitalism's digital platform data collection and advertising system-limit free will. Predictive algorithms will increasingly and tactfully "nudge" individuals toward unwitting actions. One of Zuboff's key research findings is that humans are losing control of their free wills to define their own futures. Maybe new century students already intuitively acknowledge this shift and are acting accordingly. If so, it behoves adult educators and administrators to bring transparency to this phenomenon and partner with big tech to help shape and define the shift and its implications for the classroom. Even the notion of a traditional classroom is up for grabs in this environment.

Zuboff further notes, "The twist here is that nudges are intended to encourage choices that accrue to the architect, not to the individual" (2019:295). One of the engineers she interviewed explained how "Sensors are used to modify people's behavior just as easily as they modify device behavior. . . . At the individual level, it also means the power to take actions that can override what you are doing or even put you on a path you did not choose" (293-4).

What if our efforts at behavior modification in the classroom to mitigate anxiety and inattentiveness are an exercise in futility? What if, instead of trying to modify student behaviors, we turned over classroom behavior modification to digital tech firms that are already selling software to colleges and universities? If big tech handles behavioral modification, professors would have more time to focus on content. Maybe teachers, like myself, need to be open to and inviting of full tech support through: in-class tech-modified behavioral management (e.g., vibrations and beepsto keep students alert); in-class GPS tracking using beacons (e.g., to monitor attendance and participation); and in-class nudges and rewards for good behavior, all captured and monitored through students' mobile devices, apps, beacons,

\footnotetext{
${ }^{1}$ In France, students in preschool through ninth grade are no longer allowed to bring phones anywhere on school grounds. The new policy went into effect in September 2018 as a means of addressing concerns that children are growing up addicted to mobile devices (Schechner, 2018). Without such policies in the U.S., teachers must develop new ways to garner students' attention. 
And GPS systems that accumulate data to evaluate classroom performance. The possibilities are endless as a software engineer explained to Zuboff:

"We can engineer the context around a particular behavior and force change that way. Contextaware data allow us to tie together your emotions, your cognitive functions, your vital signs, etcetera. We can know if you shouldn't be driving, and we can just shut your car down. We can tell the fridge, "Hey, lock up because he shouldn't be eating," or we tell the TV to shut off and make you get some sleep, or the chair to start shaking because you shouldn't be sitting so long, or the faucet to turn on because you need to drink more water" (Zuboff, 2019: 295-6).

For example, going full tech would be a way to directly manage new century students' inability to sit still. I have heard from professors at community colleges that when students can no longer sit still, they find ways to move around the classroom, including repeatedly walking to the front of the room to throw something into the trashcan, which is disruptive to group learning. As a result, professors place the trashcans in the hallway, thus adding another step to classroom preparation. Abeacon connected wirelessly to a software app on a student's mobile device would pick up this behavior and adjust points accordingly. If a student were to push back on a low participation grade, the teacher could direct the student to look at the data collected by the app on their phone. The technology might actually nudge students and educators to alter their behaviors toward outcomes that align with their desires, for example, to get good grades for the former and disseminate information for the latter. Facebook introduced such an app in August 2018 to show users how long they use its service and alert users to take a break from the devices (Schechner, 2018). Google and Apple both followed with the release of screen time apps to run on Androids and iPhones, respectively.

Professors are on their own with the challenges to teaching in this new environment. There is no overarching recognition by campus executives or tech providers as to how new century students are impacted by technology and how student behaviors impact the group learning process and classroom environment. Professors are learning how to adjust in real time.

\subsection{Observation \#3: Will Points Be Deducted?}

New century students perseverate on grades. To address this concern, during the first week of each semester, I take time to review the course grading scheme. I explain that everyone in the course starts the semester with zero points. Each time you have a chance to earn points, your overall number of points could go up. At the end of the semester, the total points earned correspond to the final course grade.

Five percent of each student's course grade reflects attendance, which I record at the start of each class period. Usually I have a full house. Very few students on our small campus miss classes because, as the students tell me, someone will see them later that day and ask why they missed class. Students also tell me that taking attendance face-to-face is appreciated. They see it as my personal way of checking in with each person and seeing how they are doing.

Recently, one young man pushed me on how many points would be deducted if he arrived late to class. First, I reminded him that the final grade does not reflect deducted points, but rather accumulated points earned by showing up and participating. Second, I reminded him that I only take attendance once, at the start of the class period so that we can get to course content. He pushed back saying, "but what if I walk into class one to two minutes after you've taken attendance? How many points will be deducted?"

The encounter reminded me of how anxious students are to perform at a certain pre-determined academic level. Where is this anxiety coming from? I don't think the student was trying to test me; he was genuinely engaged and conversant throughout the semester. Maybe the pressure was coming from his sports coach, known for coaching students on how to be aggressive with professors to get as many points as possible? I don't know. It's hard to know the motives of others on campus as we are all developing our own techniques to address what students present.

The fact is, professors are at times singled out by superiors for not going easy with grades - a disturbing development. Maybe a full tech approach could monitor and handle this grading problem by allowing management to change grades on their own accord after professors have submitted grades, thus freeing teachers from the political necessities outside of their concerns and control. The technology of behaviour that B.F. Skinner argued was needed to make vast changes in human behavior (1971), now exists.

\subsection{Observation \#4: Doing Nothing in Class}

My habit of walking in and around the rows of desks in the classroom gives energy and focus to our discussions about business. It also allows me to observe note taking skills. It is amazing how many students sit at their desks without taking a single note during class, not occasionally, but every day. 
When in a roaming mode, I might ask students why they are not writing anything down. They shrug their shoulders. Sometimes I will gently suggest that a student take out a piece of paper and copy the statistical grid that wedeveloped together on the board. Some get to it and engage a little more, leaving me a bit more confident that the student learned some of the day's lesson.

After one such class period, a student approached me while I was erasing the board. This young man comes to class early every day, puts his backpack on the desk unopened, and sits stone silent for the entire class period, not cracking a book or taking out pencil or paper. He is fully focused on me but does not raise his hand or join in discussions. He does not even turn his body to observe students who participate.

In Kids These Days (2018), Malcolm Harris recalls the Yerkes-Dodson Law from 1908 that correlates arousal and performance (Figure 1). At lower levels of arousal, human performance risesthrough increased attention and interest. Once optimal performance is attained, further arousal only serves to weaken performance due to strong anxiety. Has perhaps my quiet, despondent student reached his peak performance at college?

Figure 1: Yerkes-Dodson Law

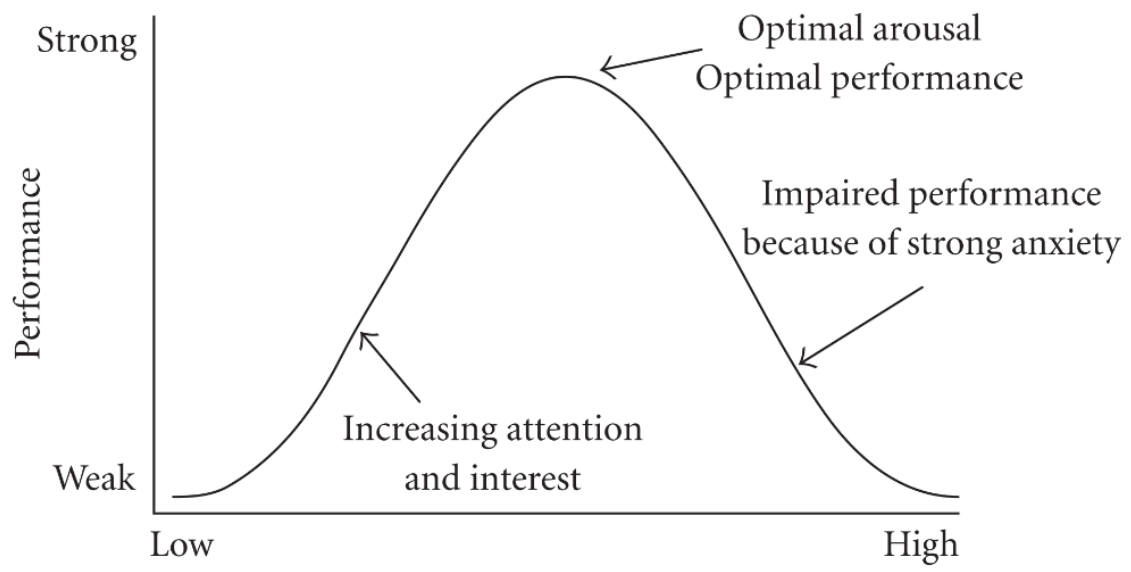

Arousal

As I am erasing the board, the student tells me that he has "accommodations due to his disabilities." This is a growing refrain from students who are admitted to college with physical, social, emotional, and/or cognitive difficulties. The student tells me that he receives class notes from a note-taker who is paid by the college to sit through the course, taking notes every day on behalf of students who indicate they are incapable of doing so on their own. This seems odd and begs the question as to how far we have gone to increase student enrollment, which in this case is to enroll a student who is incapable of taking class notes, a critical component in the learning process. All this student is capable of doing is showing up for class and sitting through the session without moving.

What am I supposed to do with such a student, representative of a growing proportion of our student population? Such students in the past did not go to college. In the 1950s and 1960s, U.S. high schools tracked blue collar or ill-prepared students into vocational education programs. In the 1970s and 1980s, schools tracked white collar, well-prepared students into Honors programs. Today we track special needs students into mainstream college classrooms, resulting in colleges spending more money on students and relatively less money on the professoriate. It will be interesting to see how this type of student progresses through college and beyond.

\section{The Impact on Teaching}

Some of us truly enjoy working with students face-to-face for a full 15-weeks to engage in live teaching and learning. Online courses and mass learning are not our thing. Wemanage classroom activities that keep us sharp and provide us with an outlet for our natural inquisitiveness about world events, which are always changing. The attention required of educators is constant and demands energy. If done well, teaching is exhausting. But demands made of us are compounded when students present as tech-tethered and anxious. Our desire to help students stay focused is constant. Nonetheless, professors find it increasingly difficult to convey to executives what it actually takes to be successful in the classroom. 
Rather than ask us what would help meet the needs of students, administrators often instead increase the number of students per course and instruct us to teach in-person and online simultaneously. ${ }^{2}$ The result is that professors are tasked to do more with less while also being monitored thru online software and voice-capturing cameras in the classroom. Why not use these same programs to monitor student behavior?

To compound the situation, some institutions require professors to clock in and out at the start and end of each class period using a computational device installed in the classroom. These machines are less than reliable and eat up precious minutes when class is supposed to begin. Frequently, IT needs to be called to get the machine to work. The process, as it is presently utilized, robs faculty members of the all-important entrance into the classroom which, if done right, calls students to attention and gives agency to the professor. It also hampers carefully-crafted and timed set activities, a major component of any adequate lesson plan.

Furthermore, professors are not consulted when decisions are made to alter our workplace environment. We regularly enter classrooms to find that slate boards have been replaced with one or two small white boards with an ever-present grey hue from built-up ink markers. We are obliged to bring our own wet cloths to wipe down the boards and then wait for them to dry before we can begin writing. We also must carry around our own set of ink markers because classrooms almost never have markers that work (except the red ones that donot fully erase). Faculty members today, unfortunately, increasingly identify with line workers as workloads increase and resources decrease.

The cheapening of U.S. classroom education emanates from these small things that make our work all the more difficult at a moment in history when student learning needs are escalating. How does a professor explain the problems encountered with proprietary course materials, trashcans, white boards, damp cloths, and red ink markers to university executives who simply do not understand? Yet, we persist in trying to improve the learning environment. Perhaps we care too much. As Anthropogenic-Luddites, many academics miss good old fashioned - and reliable-slate black boards and chalk because we want to teach well. Then again, others are glad to see the passing of black boards, with white boards simply a bridge technology to placate us as we are nudged toward full tech.

Effective teaching is all in the details. Just ask the teachers. Maybe it is time to go full tech.

\section{The Purpose of Higher Education}

There are days when professors feel they are shuffling students through a signalling machine designed to develop human capital for capitalists who have outsourced investments in education and training to colleges and universities.

Sadly, professors often do not feel that they play a useful role in cultivating intellect for its own sake. When Cardinal John Henry Newman was establishing a new university in Ireland in 1852, he delivered a series of lectures on The Idea of the University. He argued that "students who lived in a community that included the full range of intellectual endeavours and who were privy to the discourse, in and out of the lecture hall, of those professing the full range of knowledge, would stimulate a perspective of tolerance and judgment - a liberal education in the most freeing sense" (Newman,1873). Newman recognized that universities could offer specialized studies and vocational education but insisted that its central mission was "not to make students more moral or more proficient in their field of endeavour; rather, its mission was the cultivation of intellect for its own sake" (Ibid).

Rather than moving toward the creation of more intellectual spaces, today's colleges frequently mirror global capitalism's bottom line, leaving students on edge. The 1990s students were born during a period of global "aspirational individualism," which the current stage of capitalism tends to promulgate (Segal, 2018). Rather than striving to be oppositional (a healthy developmental characteristic of adolescence and youth), today's students want equal access to the starting line of an enduring capitalist race - that for many ends in heavy debt and too often depression - and espouses aggressive entrepreneurship at all cost. Psychologist Jean Twenge's analysis of children born between 1995 and 2012 concludes: "It's not an exaggeration to describe iGen as being on the brink of the worst mental-health crisis in decades. Much of this deterioration can be traced to their phones and social media" (2017:61). Unfortunately, perceived individual power through self-promotion on digital media is not the aspiration of a society that cares about the intellectual growth of young people. Maybe that is the point. As humanists, perhaps we could embrace the notion that it is all about the trans-human agenda, rather than a human agenda.

\footnotetext{
${ }^{2}$ For example, administrators want professors to use online software to post proprietary course documents (e.g., syllabi, readings, grades, assignments, attendance). Problems with this model are manifold. First, the software is usually selected by administrators, not the faculty. Second, there is no discussion of data and intellectual property rights, thus allowing private software companies to monetize our proprietary course materials. Third, when (not if) students have trouble using the site, they expect professors to provide IT support. Fourth, rather than being paid to teach one course, colleges are de facto requiring professors to teach two courses (one face-to-face and a second online) for the price of one.
} 
It is hard not to see this as a huge loss to humanity and a destructive ethos that attacks the status quo at every turn. If intellectual development is no longer the goal of higher education and students are being nudged elsewhere by big tech, what can be done?

What if we reconsidered the purpose of higher education on behalf of students born in the 2000s who will enter colleges over the next ten years? Vocational training and the all-important role of paid apprenticeships, job-specific training, and associate degrees to prepare young people for meaningful careers in non-scholarly subject matter have their merits. Maybe it is time to return to this kind of training for high school graduates in need of high skills in the absence of guilds and trade unions. Perhaps some college programs should be demoted to vocational support status, including computer programming and app creation. Most college students today do not want to become scholars who pursue doctoral studies, conduct basic and applied research, and publish academic books. Students recognize this, and hence object to having to learn foreign languages, history, philosophy, math, science, and rhetoric, with good reason. They want specific skills to get middle-class jobs. Opening up higher education is an admirable sentiment, but what have we lost in this expensive experiment? How can we dignify vocational training moving forward?

With the introduction of big tech, colleges and universities are experimenting with something radical at a time when student behaviors are without precedent. To adequately prepare new century students for the workplaces of tomorrow, it might be worth discussing the trade-offs between vocational education and classical academic education among the faculty, students, administrators, and parents of students born in the 2000s.Rather than resisting Silicon Valley's technological strategies that are disrupting higher education and making it more difficult to teach, what if we turned over the behavioral management of students to big tech, leaving professors more time to focus on course content?

At the end of the proverbial day, the virtual door may lead those Anthropocene-Luddite professors to the exit. Until then, some of us remain thankful that we still have actual doors to close in which to work out these questions and prepare students for the future in our own physical classrooms.

\section{References}

Burstein, A.G. (2016). "The Vision of the University that Arose in the Nineteenth Century May Not Survive Today's Emphasis on Vocationally Focused Education."Academe. September-October,23-26.

Council of Independent Colleges. (2015). A Compendium of Recent News from CIC Member Institutions (feat. Patrice Flynn).Independent. Fall, 37.

Flynn, P.(2017). “Autonomous Humanoid Robots as a Pedagogical Platform in the Business Classroom.”Journal of Social Science Studies,4(1), 178-188.

Han, B.C. (2017). In the Swarm: Digital Prospects. Cambridge, MA: The MIT Press.

Harris, M. (2018). Kids These Days: Human Capital and the Making of Millennials. New York, NY: Little, Brown and Company.

Krill, D. (1974). "Existential Social Work.” In F. Turner (Ed.),Social Work Treatment: Interlocking Theoretical Approaches. New York, NY: The Free Press.

Kutnowski, M. (2014, September 10). "Fighting the Internet Invasion of Childhood.”The Wall Street Journal.

McLuhan, M. (1964). Understanding Media: The Extensions of [Hu]Man. New York, NY: McGraw-Hill.

Newman, J.H. (1873).The Idea of the University Defined and Illustrated. First Edition. Dublin, Ireland: The Catholic University in Dublin.

Robertson, J. (2018). Robo Sapien Japanicus: Robots, Gender, Family, and the Japanese Nation. Berkeley, CA: University of California Press.

Robertson, J. (2007). "Robo Sapiens Japanicus: Humanoid Robots and the Posthuman Family." Critical Asian Studies, 39(3), 369-398.

Schechner, S. (2018, August 14). "France Bans Phones for Children at School." The Wall Street Journal.

Segal, L. (2018). Making Trouble: Life and Politics. New York, NY: Verso.

Skinner, B.F. (1971). Beyond Freedom \& Dignity. Indianapolis, IN: Hackett.

Twenge, J. M. (2018). iGen: Why Today's Super-Connected Kids Are Growing Up Less Rebellious, More Tolerant, Less Happy - and Completely Unprepared for Adulthood and What That Means for the Rest of Us. New York, NY: Atria Books.

Turkle, S. (2011). Alone Together: Why We Expect More from Technology and Less from Each Other. New York, NY: Basic Books.

Yerkes, R.M. \& Dodson, J.D. (1908). "The Relation of Strength to Stimulus to Rapidity of Habit-Formation." Journal of Comparative Neurology and Psychology. 18:459-482.

Zuboff, S. 2019. The Age of Surveillance Capitalism: The Fight for a Human Future at the New Frontier of Power. New York, NY: Public Affairs. 